that the stomach, spleen, and transverse colon may be displaced in a similar manner. His paper on the subject contains the first clear account of movable liver published in the United Kingdom. "A reference to the condition occurs in the new edition of "Quain's Dictionary of Medicine," where it is stated that " notwithstanding the absence of any post-mortem examination a liver, normal in form and volume, may under certain conditions of very rare occurrence be capable of considerable displacement within the abdominal cavity" (W. Johnson Smith). The condition is probably not so rare as this remark suggests. In the June number of the Canadian Practitioner for 1895 there is given a list of eighty cases collected from various sources. In 1878 twenty cases were collected by.Wickham Legg, who threw doubt on the accuracy of the diagnosis. In 1885 a monograph appeared by Landau of Berlin on Movable Liver and Pendulous Abdomen in Women. In the recently published work by Osler on Abdominal Tumours a very succinct account of a case is given. 'The latest investigations on the subject have been made by Faure, who has supplemented his researches by experiments on the cadaver. No doubt when the fact of the existence of this condition becomes more widely known and the proper method of examination is adopted numerous examples will be forthcoming.

A very typical case has come under my notice in the person of a married woman aged sixty-four years whom I first saw on Dec. 16th, 1894. She had been ill for a week with loss of appetite when jaundice set in, with constipation, clayey stools, and bilious urine. The prominent feature on examination was that hepatic dulness extended to just below the level of the umoilicus; the organ easily admitted of palpation through the thin abdominal walls, and its lower edge was extremely well defined. The heart and lungs were normal. This great hepatic enlargement seemed to negative the diagnosis of catarrhal jaundice, and it apparently belonged to that group of cases described by Bristowe as "hypertrophic cirrhosis of the liver." Other causes of hepatic enlargement, as cancer, syphilis, abscess, \&c., were easily excluded. Against the diagnosis of hypertrophic cirrhosis were the facts of the somewhat sudden onset and the absence of an alcoholic his tory. The progress of the case proved that it was ordinary catarrh of the bile-ducts, and though at first refractory to treatment by the micldle of January, 1895, the patient was in perfect health. More detailed examination of the liver during the illness revealed the following facts. The liver dulness did not begin till the costal margin (this was originally thought to be due to pulmonary emphysema). The whole mass of the liver could be easily mored through the lax abdominal walls, and when the patient arose to the erect posture the whole organ actually dropped two or three inches and could be felt in the inguinal region. 'The upper edge could not, however, be felt beneath the ribs. 'This condition of the liver remained in statu quo after the patient's recovery, showing that she bad suffered from an attack of catarrhal jaundice in a movable liver. The patient had evidently long been the subject of this condition without it affecting her general health in any particular, and it undoubtedly would never have been detected had not the jaundice directed special attention to her liver. Repeated examination failed to reveal any ptosis in the spleen or kidneys, and the patient being a thin, spare woman with lax abdominal walls examination presented no difficulty.

The comparatively few cases on record render it difficult to generalise on the subject. Nany of the cases have been associated with obvious disease sufficient to account $f(r)$ the displacement of the liver, such as spinal curvature, to mours within the thorax, and adhesions contracted as a result of inflammatory disease within the abdomen. These cases should be excluded from the category of movable livers, which depend for their production mainly on a relaxation of the suspensory ligament. Anatomically the liver should be more easily susceptible of displacement than the kidney; the latter is fixed in position by a mass of fatty tissue, while the former is merely slung up against the roof of the abdominal cavity. A displacement of the kidney almost necessarily involves tension on vessels and nerves which may be absent in a similar condition of the liver, and this would account for the existence of symptoms in the case of movable kidney and their comparative absence in that of movable liver. We are, however, confronted occasionally with symptoms of vomiting and epignstric pain in cases of movable liver. These symptoms may be of sudden onset, while a sensation of weight and dragging often forms a constant complaint. The relaxation of the suspensory ligaments of the liver must be referred to that undefined idiosyncrasy of tissue recognised in fibrous structures which consists of a loss of tone, stretching, and elongation. We know nothing scientifically about this peculiar "habit" of tissue, except that it generally exists in thin, spare subjects, mostly women who have borne numerous children. The custom of tight-lacing, as it displaces the liver, may be a factor in rendering it movable. Prolapsus uteri has frequently been noted in association with movable liver. It only remains to add that where this condition gives rise to no symptoms no interference is called for. When it has caused discomfort in the abdomen complete rest in bed has been followed by satisfactory results. Abdominal supports have been invented for some cases where this condition has produced great distress, and in a few severe cases associated with intense neurasthenic symptoms the liver has been stitched to the abdominal parietes.

Brick-lane, Spitalfields, N.E.

\section{Climital âtotes:}

MEDICAL, SURGICAL, OBSTETRICAL, AND THERAPEUTICAL.

\section{SWELLING OF THE PAROTID GLAND.}

BY WT. T. CockING, M.D. LOND.

PHYSICIAY TO THE SHEFFIELD GENERAL INFIRMARY.

THE following brief notes may be of interest in connexiorit with Mr. Raymond Johnson's very instructive paper on Some Unusual Cases of Swelling of the Parotid Gland.

In 1894 a man aged forty years, who was under treatment for dyspepsia and constipation and certain functional nervous symptoms, complained that for the last two or three years he had been much troubled with a swelling in the region of the right parotid which came on suddenly whilst eating and lasted for an hour or two. The swelling was somewhat painful and interfered considerably with mastication. $\mathrm{He}$ had found that pressure with the band caused a profuse discharge of fluid into the mouth, after which the swelling gradually lessened and disappeared The fluid had occasionally a nauseous flavour. The left gland was also affected, but much less frequently than the right. On one occasion only was an opportunity afforded of a personal examination of the swelling, which, however, had then to a great extent subsided. At that time some fulness and slight redness of the skin were detected below the right ear, and on firm pressure a copious jet of clear watery fluid was observed to escape from Stensen's duct. Nothing abnormal was at any time discovered in the mouth. Change of air and improvement in the general health resulted in the complete disappearance of the affection for some months. At the present time the attacks are considerably less frequent and give rise to much less discomfort than formerly. Sheffield.

\section{ON THE INEFFICACY AGAINST EARLY SYPHILIS OH} IODIDE OF POTASSIUM WHEN ADMINISTERED ALONE.

By Walter G. SPEncer, F.R.C.S. EnG., SURGLON TO THE OUT-PATIENTS AND THROAT DEPARTMENT OF WESTMINSTER HOSPITAL, LTC.

Soov after the introduction of iodide of potassium and as a reaction from the excessive use of mercury it was frequently given alone, but it must be now very rare to find both medical man and patient trusting entirely to this drug. Lest anyone should be tempted to tro the experiment I may record the following results, since the account given of himself by the man appears to me to be trustworthy.

The patient, a man aged thirty-one, acquired a hard sore some three years ago, which was followed by enlargement of the inguinal glands, slight pains in the limbs, and five months after the primary sore by an ulcer on the tongue. $\mathrm{He}$ 
was ordered by a medical practitioner to take ten grains of rodide of potassium three times a day, and he continued to do so for two years after the ulcer had healed. He took the medicine regularly, he never took anything else, and he never exposed himself to fresh infection. Since the ulcer healed he has not felt anything wrong with himself. Three months after leaving off the iodide, believing from what the medical man said that he was cured, he married. After three months his wife aborted. On her recovery the husband brought his wife to me. She had a characteristically dusky, scaly rash on the arm and legs, with nocturnal pains in the bones. Both husband and wife were treated with mercury, and the wife took it regularly throughout the second pregnancy, which soon began. She has now a baby one month old, whom I have seen and who appears to be perfectly healthy.

Brook-street, Grosvenor-square.

\section{“RUPTURE OF THE TERMINAL EXPANSION OF THE EXTENSOR COMMUNIS DIGITORUM.'}

By T. N. Thomas, L.R.C.P. Lond., M.R.C.S. ENG.

THE clinical notes which have lately appeared in THE LANCET under the above heading ${ }^{1}$ induce me to report the following case which is now under my observation. It differs from the others in the fact that the dislocation was compound, and the way in which it was produced is certainly peculiar and worthy of record.

A man aged twenty-five years was indulging in a game of Rugby football on Feb. 15th last, and while playing as forward was following up a long kick when one of the opposing three-quarter backs took the ball and was attempting to run cound him on his left-hand side when the forward made a grab at his opponent's jersey-a thick worsted one-with his left hand, but only succeeded in engaging the end of his middle finger in the collar, and as soon as his weight told on the finger it seemed to slip and when he looked at it a moment later it was bent at a right angle and the head of the bone was protruding through the skin at the back of the last joint. He straightened the finger and left the field. When I saw him an hour later I found the skin over the back of the last joint of the left middle finger and the posterior ligament, or, rather, what represents the ligament in that situation-namely, the terminal expansion of the extensor communis digitorum tendon-completely torn across, and when he flexed the joint the head of the second phalanx protruded through the wound. After washing thoroughly and dressing antiseptically the finger was placed on a straight splint, upon which it was kept for five weeks. At the end of that time the wound was quite healed under a scab, which came off a week later. Upon removing the splint the patient was unable to straighten the terminal phalanx voluntarily beyond an angle of about $135^{\circ}$, and though in the joint itself the movements of flexion and extension are quite free he has not yet-ten weeks after the accident-regained the power of extending it beyond that angle. The patient, whose work consists for the most part in corresponding, was not incapacitated by the accident from following his occupation for a single day. I am much encouraged by the report of Dr. Kidd's case, in which complete recovery took place after an interval of eight months, and have given my patient instructions to persevere, and I believe he very patiently and intelligently carries out my wishes.

Leicester.

"CEREBRAL MENINGITIS FOLIOWING INFLUENZA."

By Wilfred R. KingdoN, M.B. DURH.,

LATE RESIDENT MEDICAL OFFICER AT THE STOKE NEWINGTON DISPENSARY, LONDON.

I RECENTLY attended a case which presents some likemess to one recorded in the pages of THE LANCET ${ }^{2}$ some time ago.

I first saw the patient, a boy fourteen and a half years of age, on a Sunday, when he presented the following symptoms : severe frontal headache, excessive lacrymation together with pain on pressing over the eyeballs, aching

1 THE LANCET, Feb. 29th and March 28th, 1896 THE LaNCET, Feb. 22nd, 1896. pains in the lumbar region and legs, furred tongue, anorexia, somewhat scanty and high-coloured urine, constipation, a temperature of $104.2^{\circ} \mathrm{K}$., and a pulse of 117 . From what the boy's mother told me I came to the conclusion that the illness had commenced with a rigor and some sickness, but apparently no actual vomiting. There seemed to be no doubt whatever but that the boy was suffering from influenza, and I ordered him seven grains of phenacetin powder to be taken at once and a mixture containing quiniæ sulphas and liquor ammoniæ acetatis. The next day I found the patient in a much more comfortable condition; the temperature was $100 \cdot 8^{\circ}$ and the pulse 100 . The pains were better, the tongue was slightly less furred, and he could be induced to take a little milk pudding. This improved condition continued for a week, but his temperature never fell below $100^{\circ}$. At the end of this period he began to lack interest in things which were going on about him; he had a dull, almost stupid expression; he did not seem to understand what was said to him, and at times he talked incoherently and picked at the bedclothes. The ophthalmoscope revealed optic neuritis; there was intolerance of light, the head was slightly retracted, and the tache cérébrale could be demonstrated, but the abdomen was not boat-shaped. The preponderance of evidence certainly pointed to cerebral meningitis. This condition of affairs had been going on for just three days when I was called in great haste to see the boy, "as he was in a fit." On arrival I found the patient seized with tonic contractions of nearly every muscle of the body; there was opisthotonos, and both sides of the body seemed about equally affected. He soon relapsed into a comatose condition and died in about ten and a half hours after the onset of the spasmodic contractions, notwithstanding the fact that he had constant care, frequent liquid nourishment, and stimulants, to say nothing of numerous drugs. Potassii bromidum, quiniæe sulphas, liquor ammoniæ acetatis, phenacetin, sodium salicylate, and other things were alike of no avail. No necropsy could be obtained, but there seemed to be no doubt that it had been a case of cerebral meningitis.

Now, how was this meningitis caused? A careful examination revealed no condition likely to give rise to the disease, and the question seems to be: Is meningitis to be put down as one of the sequelæ of influenza? I cannot give any reason why the one disease should lay the foundation of the other, neither is it my wish to advance any theory. It may be that this was but a coincidence and that lowered vitality was the predisposing cause alike of both; however, I have given only the simple facts, and it is thus open to each and every reader to take his own view of the case.

Queen's-crescent, N.W.

The Portsmouth Waterworks.-The proposal of the Portmouth Corporation to purchase the enormous undertaking of the water company was advanced a distinct step at a special meeting on April 28th. A special committee had had several interviews with the directors of the company, and the present scheme stands as follows: It is estimated that a total amount of consolidated stock will be required to the extent of $£ 1,040,000$. The shareholders will receive $£ 915,000$ in stock as representing the full dividend of $£ 27,448 ; £ 1 C 4,500$ will be absorbed in the payment of loan capital; £3550, seven years annuity for the secretary ; $£ 5880$ for seven years directors' fees; and $\$ 4113$ for unpaid back dividends. The estimated legal costs of the necessary Bill in Parliament are $£ 6000$, or a total, as above stated of nearly $\& 1,040,000$. Two and a half years ago, when the purchase negotiations fell through, the nett increase of the company's revenue was put at $£ 600$ a year ; now it is over $£ 1000$, and so the directors ask more money for their concern. The gross revenue of the company is $£ 53,000$ a year and grows, of course, with the town, whose rateable ralue last year increased by $£ 12,000$. It is calculated that with ninety years' redemption of the stock the corporation would gain by the transaction in the form of a small actual yearly profit; at eighty or eighty-five years' redemption there might probably be a small deficit to recoup from the rates. There was some hesitation apparent in the speeches at the council meeting, but as the committee's report was carried by thirtyone votes to two it seems likely that the corporation, remembering the mistake of two years ago, will not allow it to recur for the sake even of a thousand or two paid on what they may consider heavy claims. 